\title{
25 Research Square \\ Peer Supported Open Dialogue in the National Health Service: Implementing and Evaluating a New Approach to Mental Health Care
}

\section{Catherine Kinane}

Combat Stress

\section{James Osborne}

Kent and Medway NHS and Social Care Partnership Trust

Yasmin Ishaq

Kent and Medway NHS and Social Care Partnership Trust

\section{Marcus Colman}

Kent and Medway NHS and Social Care Partnership Trust

Douglas Maclnnes ( $\nabla$ douglas.macinnes@canterbury.ac.uk)

Canterbury Christ Church University

\section{Research Article}

Keywords: Open dialogue, mental health, community psychiatry, peer support, social network, carer support, wellbeing, social adjustment, functioning

Posted Date: March 8th, 2021

DOI: https://doi.org/10.21203/rs.3.rs-279376/v1

License: (c) (i) This work is licensed under a Creative Commons Attribution 4.0 International License. Read Full License

Version of Record: A version of this preprint was published at BMC Psychiatry on February 22nd, 2022. See the published version at https://doi.org/10.1186/s12888-022-03731-7. 


\section{Abstract}

\section{Background}

Open Dialogue, an approach to mental health care which is based on collaboration between an individual and their family and social network, originated in Western Lapland in the 1980's and has been developing internationally. Our quest for better approaches to Mental Health Care with improved carer and service user experience led us to develop and test a model of Peer Supported Open Dialogue (POD). There is no research currently looking at the impact of a standalone POD model in an NHS community team so this study evaluates its implementation, clinical effectiveness and value to service users, their families and NHS staff.

\section{Method}

50 service users treated by the POD Team were recruited with additional participants from family and wider social network. Questionnaires covering wellbeing, functioning, satisfaction were collected through validated scales completed at baseline, three and six months. Data regarding adherence was collected following each network meeting.

Data from electronic medical records was collected looking at functioning, contact rate, those in employment or full-time education and the mean bed days per episode of care between service users receiving POD compared to traditional services.

\section{Results}

Service users treated were young people with a mean age of 35 years, slightly more males than females. The approach was effective on service user reported measures of wellbeing and functioning. Clinician reported measure showed better outcomes than treatment as usual at the six month point. There was a marked increase in perceived support by carers which increased across the study. Over half the meetings were attended by carers. The POD group had greater face to face contact, longer contact times and an important clinical difference in the number of bed days used. Clinician adherence to the model was very high. The Community Mental Health Survey showed high satisfaction rates for service users including carer involvement.

\section{Conclusions}

It was possible to transform to deliver a clinically effective POD service in the NHS. This innovative approach provided continuity of care within the social network, with improved carer support and high satisfaction for service users, carers and clinicians.

Trial registration: (isrctn.com/ISRCTN36004039. Retrospectively registered 04 January 2019.

\section{Background}

Open Dialogue is an approach to working with mental health crises that originated in Western Lapland, Finland $[1,2]$. It has gained substantial international interest due to its emphasis on social network support, generating dialogue about the mental health crisis and involving the service user in all decisions regarding treatment [3]. Open Dialogue not only describes a way of being with the other, without conditions, but also a way of 
organising a mental health service to make dialogue and continuity of care possible. The seven organising principles that emerged from the work in Western Lapland [4,5] are:
i. immediate help
ii. a social networks perspective,
iii. flexibility and mobility,
iv. team's responsivity,
v. psychological continuity,
vi. tolerance of uncertainty
vii. dialogism.

POD is integrative and inherently democratic, empowering of the service user and embraces a social network approach which brings together the social and professional network to create space were all find words for their experiences with transparent decision making. The aim of dialogic practice in Open Dialogue is to listen, and responsively respond, generating dialogue between all participants unlike in traditional treatments where methods or interventions are planned for a specific diagnosis, to reduce symptoms or change thinking. In network meetings, clinicians reflect between themselves in the presence of the service user and their network, usually family with the aim of making sense of the crisis. Treatment decisions are made by all participants with the expressed aim of avoiding hasty treatment planning.

Support for the Open Dialogue model

Evidence from the Open Dialogue (OD) service in Finland indicated those receiving the service had lower levels of antipsychotic medication use, lower rates of relapse and hospitalisation and were more likely to return to work or education compared with users of traditional services $[1,6]$. These positive findings were maintained at a twenty year follow up [7]. Several other countries have embraced the OD approach, with initiatives in the United States and several countries across Europe, including the United Kingdom, Austria, Italy, Germany, Poland, Finland, Norway, Denmark and Australia. Although the evidence to support the application of Open Dialogue looks promising a systematic review of the published evidence for OD interventions [8] reported the studies undertaken were mainly qualitative, cross-sectional and small scale, with a lack of high-quality empirical publications. Issues noted included variable adherence to the model and differences in inclusion criteria leading to low internal validity of the evidence along with potential bias from the researchers. These methodological limitations led the reviewers to question the validity of the conclusions drawn and conclude that more robust research designs were required to assess the effectiveness of Open Dialogue.

\section{Traditional Services}

The study is based in the NHS mental health trust based in Kent, which is a semi-rural county in South East England where people experiencing a mental health crisis are typically offered a referral to, either the Crisis Resolution and Home Treatment Team (CRHT) or, the Community Mental Health Team (CMHT). The CRHT consists of a multidisciplinary team of nurses, occupational therapists, support workers and psychiatrists providing urgent $24 / 7$ response to people in a mental health crisis. The CMHT is a multidisciplinary team of nurses, occupational therapists, psychologists, support workers and psychiatrists providing routine responses 
to people with secondary care mental health needs during 9am to $5 \mathrm{pm}$ on weekdays. Service users presenting in crisis are moved to another team when the crisis has diminished. Different teams serve different parts of the Service User pathway.

Peer Supported Open Dialogue (POD) in Kent

Peer Supported Open Dialogue is an adaption of Open Dialogue model specifically designed to be applied for the National Health Service in the UK [9]. POD adheres both to the organising principles of Open Dialogue as well as the key elements of dialogic practice whilst also including peer support workers as trained and equally active members of the team. Peer support workers have an insight into the difficulties of using mental health services and by sharing their own lived experiences they can build trust and engage people in their treatment [10]. This role also increases social inclusion for service users, helps stabilise subsequent employment or education [11], and improves clinical outcomes with less inpatient bed use [12]. It has also been proposed peer support workers may be valuable in situations where people have little or no social support network available peer support workers may be useful as the peer can, through a process of mutuality and reciprocity walk alongside individuals and families, supporting them to build new networks of support [13]. In Kent we introduced a standalone team working with the Peer Supported Open Dialogue model [14]. The option we discounted was to integrate POD into an existing CMHT as this may have limited fidelity to the model. The POD team was very small at the outset, six whole time equivalent staff and has grown to nine whole time equivalent staff.

Training

All POD staff underwent a one-year training course provided by the Academy of Peer Supported Open Dialogue (APOD) [15]. Members of the POD team, including peer workers had either completed a one year diploma in Open Dialogue practice or were in the process of completing their training. One person, the team manager who also delivered clinical care, undertook the post graduate qualification in Dialogical Approaches in Couple and Family Therapy, psychotherapy trainers training (supervisor level training) accredited by the University of Jyvaskyla, Finland.

\section{Criteria}

We agreed the criteria for the team, to accept those presenting in crisis in a new episode of care, whether via the Single Point of Access or sent by the Crisis Resolution and Home Treatment Team. These teams determine eligibility to NHS secondary specialised mental health care. Due to the small size of the team, it accepted five referrals per week. Care was delivered through network meetings which were attended by staff including peers with two usually allocated to attend each network meeting.

Adherence and Fidelity to Model

We used the fidelity criteria [5] after every POD network meeting and self-audited our practice against the criteria to ensure fidelity to the original approach.

Network meetings 
The social network sets the primary agenda for the meeting. It became apparent during the course of delivery that the reflective process within the meeting became increasingly important in facilitating curiosity and greater understanding of what had happened and was happening, and this process informed the collaborative decision-making at the end of the network meeting. Planned network meetings were based on need as perceived by the service user and their network and determined at the end of each network meeting.

\section{Supervision}

The model requires a reflective space for clinicians to have time to consider their practice and relational way of being with each other and the service users and social network [16-18]. This enabled a deeper understanding of each other as practitioners but also helped to take account of power positions in meetings including between practitioners. Peer reflective supervision occurred weekly with generally no external facilitator [17]. Essentially this was a model of reflective peer supervision for all members of the team. It is important to note that no clinical decisions were made in this supervision space as those decisions remained in the domain of the social network meetings.

Location

Our team is located in Kent in a University City. This ensured the service users seen were a mix of those living in the small city as well as the countryside. The team functioned alongside the existing mental health services which include the traditional teams entry points for inpatients; crisis resolution and home treatment, community mental health team, early intervention in psychosis and specialist teams. There were major challenges to develop a service that did not follow the established pathways for entry into care under traditional team boundaries. There were further challenges in continuing to work with people until they felt they had achieved recovery and were ready for discharge rather than the clinician and service design making those decisions as is traditional in the medical model.

We had to remain within the governance structures of a large NHS trust. The standard operating procedure written for the team included agreements with all parts of the system as to how the POD team would interface and work safely within and seamlessly with the usual system of mental health care delivery. For example, we had to consider the Care Programme Approach (care and treatment plan) and risk assessment and management whilst continuing to work dialogically. It was essential not to increase risk to any service user or family member or indeed staff member during the course of this innovation. As you would expect we monitored quality and performance in line with all other Trust services.

A qualitative study examining the introduction of a POD service in England reported that clinicians positively viewed this way of working [19]. There were, however, mixed views from service users, including being unsure as to the purpose of the network meetings and finding the reflective conversations strange, though, the majority felt listened to and understood. The study was carried out during the training of the clinicians so may not accurately reflect the opinions of an established POD service from users and professionals.

The evidence base for the open dialogue approach, in a UK setting, remains sparse and currently there has not been any published quantitative data examining the POD model $[19,20]$.

Aims

Page 5/19 
The aim of this study was to examine the impact of implementing a POD service in a mainstream NHS setting and compare outcomes with traditional services. The study also aimed to gain an understanding of the experiences of the family, carers and social network, and also assess how closely the POD team were adhering to the key elements of the Open Dialogue Approach. These were achieved through our primary and secondary objectives:

Primary objectives:

1. To examine service user clinical outcomes of wellbeing, experience of the service and impact on daily routine during the course of a POD intervention

2. To examine the wellbeing of the family and social network receiving treatment in the POD service.

Secondary objectives

1. To compare the health and social functioning scores of service users receiving POD compared to those receiving traditional services

2. To record the frequency and contact use of people receiving POD compared with those receiving CRHT and CMHT services.

3. To record the number of service users receiving POD who were in employment or full-time education

4. To record the level of adherence to the Open Dialogue model by POD practitioners.

5. To record the mean length of bed days per episode of care for service users receiving POD.

6. To compare the mean length of bed days per episode of care for service users receiving POD with those with those receiving treatment from traditional services

\section{Methods}

Design

This was an exploratory study using an observational design with participants recruited to the study followed up for six months following on from their first POD meeting.

Participants

The study was conducted in one locality; a University City in Kent, South East England. Three participant groups were recruited: service users, family and/or social network members, and POD practitioners. Service users were eligible if they were aged between 18 and 70, were experiencing a mental health crisis and would have normally been seen by a traditional mental health service; in this case the Crisis Resolution Home Treatment team (CRHT). People with a learning difficulty or dementia or first episode psychosis were seen by other services and excluded from the study. A convenience sampling approach was used with all service users meeting the eligibility criteria and who had capacity to consent to participate being invited to participate in the study.

Service users coming in to the service were assessed regarding capacity to consent and ability to take part by the clinical team, and information sheets left with them prior to informed consent being obtained. This 
approach continued until a target of 50 participants was reached. We also recruited any member of their family or social network who consented to the study. The choice to cut off recruitment at 50 participants was guided by the central limit theorem with the sampling distribution of the mean of any independent random variable considered normal if the sample size is large enough. A figure of 50 is normally considered a large enough number [21]. This also allowed us to undertake data analysis under the assumption that the data is normally distributed.

During the period of the study, 171 users received the POD service while 2263 service users completed an episode of care by either the CMHT or CRHT. These two groups were used to compare contact rates, HoNOS [22] and hospitalisation rates. The Trust routinely collects HoNOS data, hospitalisation data and contact data so the overall scores of service users referred to the POD service and the two community services were also recorded to allow a comparison to be made.

Intervention

Service users accessed the POD service in the same way as other local mental health services Individuals who met the eligibility criteria for secondary/specialist mental health care, were in mental health crisis and needed an urgent response were referred to the POD team who followed the principles of Open Dialogue practice noted above. The multidisciplinary POD team comprised of clinicians from a variety of professional backgrounds and included peer support workers and carers who had trained in POD [9]. The team provided both urgent and routine responses. Following on from an initial referral, a POD practitioner from the team contacted the service user to ask if the POD team could meet with them at a convenient time and location. They were also asked who else they would like to attend. The initial POD meeting consisting of the clinical and social network participants was held within 24 hours of first contact with the POD team. The duration and frequency of POD meetings were not fixed and were decided within the meetings using a case-by-case approach. During the initial stage of a mental health crisis, meetings could take place every day for the first ten to twelve days and could last for up to two hours to foster an adequate sense of security. Subsequent meetings were organised less frequently according to a joint plan agreed by all parties. Similarly, a point of discharge was a shared decision between service user, social network and clinicians.

\section{Measures}

Demographic information was recorded from the case notes. Table 1 outlines the measures used to assess service user's clinical outcomes, wellbeing, and impact on daily routine, family/social network support, and the level of adherence to the Open Dialogue model by POD practitioners, as well as the assessment time points. Measures completed by service users were compiled into questionnaire booklets and were either completed with the help of an independent researcher or completed autonomously. The data relating to length of hospital stays was collected from the Trust's audit team and details information related to all service users receiving POD and those receiving similar Community Mental Health Services between 1st February 2017 and 31 st January 2019. As POD performs the functions of both CRHT and CMHT, data for these were combined to serve as the most accurate comparator. The number and frequency of contacts with the POD team and the two community services were also collected centrally.

Table 1: Outcomes Measures 


\begin{tabular}{|c|c|c|c|}
\hline Name & Measuring & Description & $\begin{array}{l}\text { Measured } \\
\text { at }\end{array}$ \\
\hline $\begin{array}{l}\text { Health of the Nation } \\
\text { Outcome Scales } \\
\text { (HoNOS) } \\
{[22]}\end{array}$ & $\begin{array}{l}\text { Health and social } \\
\text { functioning of people } \\
\text { with severe mental illness }\end{array}$ & $\begin{array}{l}12 \text { items measured on } 5 \text { point scale; } \\
\text { Range 0-48; Higher scores equate to } \\
\text { lower functioning (clinician rated). }\end{array}$ & $\begin{array}{l}\text { Baseline } \\
\text { and } \\
\text { Discharge } \\
\text { from } \\
\text { service }\end{array}$ \\
\hline $\begin{array}{l}\text { Shortened Warwick- } \\
\text { Edinburgh Mental } \\
\text { Well-being Scale } \\
\text { (SWEMWBS) } \\
\text { [23] }\end{array}$ & Mental Wellbeing & $\begin{array}{l}\text { 7-item measure; 5-point scale; Range 7- } \\
\text { 35; High mental wellbeing } 28 \text { or above; } \\
\text { (self-reported by service user). }\end{array}$ & $\begin{array}{l}\text { Baseline, } \\
3 \text { and } 6 \\
\text { months }\end{array}$ \\
\hline $\begin{array}{l}\text { Work and Social } \\
\text { Adjustment Scale } \\
\text { (WASAS) } \\
\text { [24] }\end{array}$ & $\begin{array}{l}\text { Impairment in } \\
\text { functioning }\end{array}$ & $\begin{array}{l}\text { 5-item measure; 9-point scale; Range 7- } \\
35 \text {; Higher scores equate to greater } \\
\text { impairment (self-reported by service } \\
\text { user) }\end{array}$ & $\begin{array}{l}\text { Baseline, } \\
3 \text { and } 6 \\
\text { months }\end{array}$ \\
\hline $\begin{array}{l}\text { NHS Community } \\
\text { Mental Health } \\
\text { Survey (CMHS) } \\
\text { [25] }\end{array}$ & $\begin{array}{l}\text { Experiences of health } \\
\text { and social care received } \\
\text { through NHS mental } \\
\text { health services }\end{array}$ & $\begin{array}{l}42 \text { questions. Mean score recorded } \\
\text { (from } 1-10) \text {. Higher score equates to } \\
\text { more positive experiences (self-reported } \\
\text { by service user) }\end{array}$ & $\begin{array}{l}\text { Baseline, } \\
3 \text { and } 6 \\
\text { months }\end{array}$ \\
\hline $\begin{array}{l}\text { Carers Wellbeing } \\
\text { and Support Scale } \\
\text { (CWS) } \\
\text { [26] }\end{array}$ & $\begin{array}{l}\text { Carers satisfaction of } \\
\text { support received }\end{array}$ & $\begin{array}{l}\text { 17-item 'support' sub-measure; 4-point } \\
\text { scale. Range 0-51. Higher scores equate } \\
\text { to perceived greater levels of support } \\
\text { (self-reported by family/carer) }\end{array}$ & $\begin{array}{l}\text { Baseline, } \\
3 \text { and } 6 \\
\text { months }\end{array}$ \\
\hline $\begin{array}{l}\text { Adherence Measure } \\
\text { for Peer- Supported } \\
\text { Open Dialogue } \\
\text { Practice } \\
\text { [5] }\end{array}$ & $\begin{array}{l}\text { Adherence to the key } \\
\text { elements of Open } \\
\text { Dialogue }\end{array}$ & $\begin{array}{l}\text { 17-item } 4 \text { point scale; Mean score } \\
\text { recorded (range } 1-4 \text { ). Higher scores } \\
\text { indicate greater adherence to the model. } \\
\text { (self-reported by clinicians) }\end{array}$ & $\begin{array}{l}\text { Each POD } \\
\text { network } \\
\text { meeting }\end{array}$ \\
\hline
\end{tabular}

Statistical Analysis

IBM SPSS Statistics v22 software was used for the statistical analysis using anonymised data. ANOVA was carried out to test across the three time periods with a post-hoc test (Tukey's HSD) used to determine which conditions were significantly different. T-test scores were calculated to examine the differences in HoNOS scores between baseline and 6 months. To compare the POD results with those of the routinely collected scores for the traditional services, $T$ test scores were calculated. For all parametric analyses Levene's test for equality 
of variances was carried out in order to establish homogeneity of variance. In all cases the variances were not significantly different and parametric tests were appropriate.

\section{Results}

During the study period 113 service users were approached to participate in the study until the required 50 participants were recruited; a recruitment rate of $44.2 \%$. Of those further 63 service users, 18 (15.9\%) declined to take part, 4 (3.5\%) were unable to give informed consent, 24 (21.2\%) were either discharged or disengaged with the service before they could be recruited, and the remaining 17 (15\%) did not take part for unknown reasons. In addition, 25 carers consented to take part in the research although one carer did not complete any outcome measures. The demographic characteristics showed slightly more male participants (27 - 54\%) with the overwhelming majority ( $47-94 \%)$ being white British. The mean age was 35.8 years.

Attrition

Every participant completed the baseline measures; 40 (80\%) completed the 3 month measures and thirty-seven (74\%) completed the 6 month measures. The main reasons for not completing the measures were either that the service user had disengaged from the service or they had been discharged from the caseload.

Network meeting attendance

We examined the attendance at the first ten network meetings for all participants, or for all meetings with those participants discharged before they completed ten network meetings. This resulted in records of attendance for 467 meetings. Just over half the meetings (245 - 52.5\%) were attended by the service user and other network members while the remaining meetings (222 - 47.5\%) were solely with the service user. In those meetings where network members attended, the most common attendee was the spouse or partner of the service user (97 instances; occurring in $39.6 \%$ of the network meetings). This was followed by one parent (74 - 30.2\%), both parents (31 - 12.7\%), friends (30 - 12.2\%), adult children or other relatives (24 - 9.8\%), siblings (20 - $8.2 \%)$ and others $(5-2 \%)$.

\section{Clinical symptoms, experience of service, wellbeing, and impact on daily routine}

Table 2 presents the outcome measures from three self-report measures and one clinician-rated measure at three time points. All four measures show improvements from the baselines score at the 3 and 6 month time point with statistically significant improvements recorded in the SWEMWBS, WASAS, and HoNOS scores.

Table 2. Clinical Outcomes, Wellbeing, Clinical Experience and Impact on Daily Routine Scores 


\begin{tabular}{|c|c|c|c|c|c|c|c|c|}
\hline \multirow[t]{2}{*}{ Measure } & \multicolumn{2}{|c|}{ Baseline } & \multicolumn{2}{|c|}{ Three Months } & \multicolumn{2}{|c|}{ Six months } & \multicolumn{2}{|l|}{ ANOVA } \\
\hline & $\mathrm{n}=$ & Mean (sd) & $\mathrm{n}=$ & Mean (sd) & $\mathrm{n}=$ & Mean (sd) & $F(d f)$ & Sig. \\
\hline \multirow[t]{2}{*}{ SWEMWBS } & 49 & $16.84(5.73)$ & 40 & $22.43(5.80)$ & 37 & $21.16(5.63)$ & 13.668 & $p=<0.001$ \\
\hline & & & & & & & {$[2,123]$} & \\
\hline \multirow[t]{2}{*}{ WASAS } & 50 & $24.94(9.41)$ & 38 & $18.66(10.78)$ & 36 & $16.69(11.35)$ & 7.520 & $p=0.001$ \\
\hline & & & & & & & {$[2,121]$} & \\
\hline \multirow[t]{2}{*}{ CMHS } & 45 & 8.44 & 40 & 8.93 & 37 & 9.19 & 2.174 & $p=0.118$ \\
\hline & & $(1.88)$ & & $(1.86)$ & & $(0.97)$ & {$[2,118]$} & \\
\hline \multirow[t]{2}{*}{ HoNOS } & 50 & $21.26(6.65)$ & $\mathrm{n} / \mathrm{a}$ & $n / a$ & 42 & $12.31(7.26)$ & $7.903^{*}$ & $p=<0.001$ \\
\hline & & & & & & & (41) & \\
\hline
\end{tabular}

$*$ T test score

The SWEMWBS scores show there was a significant improvement in mental wellbeing between baseline and the 3 month timepoint. The mean score at 6 months is slightly less than the 3 month score but still significantly more than at baseline.

The WASAS scores record ongoing improvement in self-reported functioning in work and social activities at each time point with the scores between baseline and 6 months being significantly different.

The HoNOS scores indicate there was a significant reduction in clinician-reported symptom severity measured by HoNOS scores between baseline and 6 months/discharge time point.

The CMHS scores indicate an improvement in the care experiences the service users receive with an increase in scores at each time point. These increases were not statistically significant. However, the scores at all three time points compared favourably with the overall Trust and national scores for satisfaction with the 6 month POD service recording a mean of score 9.19; compared to the 2017 Trust score of 6.51; and the 2017 national score of 7.03

\section{Family, carers and social network support .}

Table 3 shows the family members/carers views of the perceived support they received from the POD service. The CWS Support sub-scale scores record that an increase in support was reported between baseline and 3 months with this support score increased at the 6 months' time point. Post hoc testing revealed the improvement in support was significant between baseline and 6 months.

Table 3 : Carer Support Sub-scale Scores 


\begin{tabular}{|llllll|}
\hline CWS Support Sub-scale & Baseline & Three Months & Six months & ANOVA & \\
& $\mathrm{n}=21$ & $\mathrm{n}=16$ & $\mathrm{n}=13$ & & \\
& Mean (sd) & Mean (sd) & Mean (sd) & $\mathrm{F}(\mathrm{df})$ & Sig. \\
\hline $41.67(7.96)$ & $46.69(5.85)$ & $48.00(3.85)$ & 4.743 & $\mathrm{p}=0.01$ \\
& & & & {$[2,47]$} & \\
\hline
\end{tabular}

\section{Adherence to the POD model by staff}

Clinicians completed dialogical adherence ratings these together after returning from a network meeting. 115 measures were completed. The overall mean score was 3.62 (sd 0.28) indicating high self-reported adherence to the model.

Employment

At baseline $22 \%$ were in full-time employment $(n=11)$ and $12 \%$ were in full-time education $(n=6)$. At the six month point $30 \%$ were in full-time employment $(n=15)$ and $18 \%$ were in full-time education $(n=9)$, indicating a $14 \%$ increase in take up of employment or education.

\section{Comparison between POD service users and community service users, CMHT/CRHT}

HoNOS

The mean HoNOS scores at baseline (point of entry into the POD and the two community services) were: POD 17.64 (sd 6.12), and community services 17.21 (sd 6.73), indicating similar levels of health and social functioning for users referred to the POD and community services. At the 6 month time point, there was a small non-significant difference in the mean scores with 15.67 (sd 7.59) recorded by the 171 members of the POD group compared to 15.51 (7.23) reported by the 2263 users in the community services cohort, $t(2434)=0.27, p$ $=0.79$.

Hospitalisation rates

During the period of the study, the mean number of bed days per episode of care were recorded for all closed cases (i.e., those who had completed their care and treatment). The 32 service users receiving the POD service had a mean of 0.44 (sd 2.8) bed days in hospital during their complete period of continuous care starting from their first referral with to date of their final discharge. During this period, 67 closed cases were reported for users seen by the two traditional services. The corresponding mean number of bed days from CRHT/CMHT services was 2.24 (sd 23.86). Although the number of bed days was over five times higher in the community service group the difference between the two services in bed use was not statistically significant; $\mathrm{t}(99)=0.61, \mathrm{p}=0.54$.

\section{Contact rates}

The mean duration of contact between the services and users of the two services was 88.14 (sd 89.91 ) for the POD group and 61.37 (sd 86.88) for the community cohort. The t-test analysis reported the difference was not significant; $t(99)=1.42, p=0.16$. The POD group also reported greater face-to face contact with a mean of 
95.42 (sd 92.36) minutes compared to 74.65 (sd 95.15)f or the CRHT/CMHT group. Again, the difference was non-significant; $\mathrm{t}(99)=1.03, \mathrm{p}=0.31$.

\section{Discussion}

This is the first study to evaluate the POD approach in a large NHS mental health trust delivering a standalone POD team, as complete care to NHS mental health service users within a community setting. The group of service users treated were predominantly young people, mean age 35 years, slightly more male than female in an area where generally the population is white British, with a student population attracted by the local universities. There is an emerging focus on co-production and active citizenship in recovery [27] such that there is a strong case for enhancing the implementation of shared decision making to promote recovery. This is fundamental to POD which is democratic, collaborative and sees each person in the network meeting as an equal or potential partner in recovery. In a Service User led report it was identified that most service users who took part in the project which gathered their views, felt that social approaches to mental health, which take account of the whole person and wider societal issues affecting them are the most helpful [28].

\section{Clinical Outcomes and comparison to TAU. Employment and education data}

It has been found it to be effective on all clinical measures of service user outcomes showing benefits in terms of recovery and function and keeping more people in employment and education from three self-report measures and one clinician-rated measure at three time points. All four measures show improvements from the baselines score at the 3 and 6 month time point with statistically significant improvements recorded in the SWEMWBS, WASAS, and HoNOS scores.

The HONOS scale showed clinically better results than treatment as usual at the six month point, although statistically non-significant, however scores were higher in POD at the outset and lower at the six month point. The HoNOS scores indicate there was a significant reduction in clinician-reported symptom severity measured by HoNOS scores between baseline and 6 months/discharge time point. Preliminary comparison data from the local crisis and community teams show that, according to the HoNOS data, the POD team is seeing service users with slightly worse or similar symptom severity as the crisis team and results are at least as good.

The SWEMWBS scores show there was a significant improvement in mental wellbeing between baseline and the 3 month timepoint. The mean score at 6 months is slightly less than the 3 month score but still significantly more than at baseline.

The WASAS scores record ongoing improvement in self-reported functioning in work and social activities at each time point with the scores between baseline and 6 months being significantly different.

These results show there are the benefit of reduced symptom severity, improved mental wellbeing and increased engagement in work and social activities. These improvements go hand in hand with a better quality of life for the service users and indicates reduced distress and care needs with a better prognosis for their future. This is of great significance to service users [28].

Evaluation is the basis for improving care and it has been suggested that mental health care services can be evaluated on two dimensions; whether they are beneficial or harmful, and whether they offer value for money 
[29]. This service was demonstrated to be beneficial to service users in terms of clinical outcomes and overall satisfaction. It incorporates shared decision making and the option to mobilise social support networks with a high level of choice offered to the service user and this may address national quality issues of service user satisfaction identified by the Care Quality Commission [30]. A review of the evidence for Open Dialogue found that there has been considerable variation in how the Finnish OD model has been implemented in different locations, making comparisons unreliable [8]. This POD service followed the treatment principles outlined by the Finnish researchers and developers of the fidelity criteria [1,5]. Data from self-reported model adherence showed that these principles were followed closely.

This model was set up from scratch to test it in the NHS and this has proved possible. There were a number of barriers to this POD team model as contrary to most NHS service models it worked trans-diagnostically and across crisis and recovery discrete pathways. The POD team also in reached to inpatient services

National service user experiences are measured each year using the CQC Community Mental Health Survey. Our results show that service users rated the POD service more highly than other local and national data and this suggests that this approach addresses some outstanding issues with mental health services around service user satisfaction.

Clinical outcomes were consistent across mental wellbeing and work/social adjustment (self-reported) and HoNOS scores (clinician-reported) and showed that this approach is clinically effective with significant improvements across all measures. Employment and education data were less indicative but these data were collected over six months and a longer follow-up study is required.

\section{Wellbeing of family and social network}

The CWS support scale scores compare favourably with the findings of Quick during the development of the measure who reported a mean score of 32.23 (sd 12.57) among 361 carers of people with mental illness and/or dementia. The 6 month score of 48.00 in our study shows a marked increase in the how carers perceived they were being supported by the POD team. It is also striking to note that at baseline the POD participants record a score of 41.67 suggesting that carers acknowledged the initial support provided by the POD service even at this early stage of the intervention.

There seems to be a wish for the involvement of carers as over half the meetings were attended by carers. When carers are involved in care, they are more involved in the service users recovery and with reduced risk of mortality by suicide [31]. One of the strengths of the POD model lies in the mobilisation of the social network. In this study it was found that almost half of the meetings did not have any network members present. Possible reasons for this could be due to stigma or a low level of social support in this population overall. Despite this finding, the high levels of satisfaction suggest that the POD team provided suitable support for the individuals when other support was absent or unwanted. This could be explained by the POD team practice of engaging with important voices through the service user as a way of understanding

\section{Frequency of contact}

There was greater face to face contact for the POD group and longer contact times. This is congruent with the POD model which is responsive to need as perceived and expressed by the service user rather than on the basis 
of appointment slots or capacity of clinicians in clinics unless a service user declares their issue urgent when they then receive duty worker support. The decision about frequency of contact is made by the service user with the team and this may have been empowering for the service user, a collaborative approach which may have improved the outcomes for service users [1]. This could be explored in greater detail in future studies.

\section{Adherence}

There was very high adherence to the model and this was important as there are a number of attempts to set up OD treatments around the world which struggle to be faithful to the model and so this study has truly looked at the OD model modified only by the addition of peer workers to the clinical team. The adherence to the model by the clinicians suggests that the model could be applied on a wider basis and the consistency of the offer being maintained ensured psychological continuity for service users.

\section{Bed days}

There was an important difference in the number of bed days used which although not found to be statistically significant, probably due to a small sample size, is clinically valuable and small reductions are highly impactful on cost of care within the health system as a whole. Preliminary bed-day data appears promising, although a longer term data analysis will be needed before conclusions can be drawn about cost-effectiveness and value for money.

\section{Overall}

In this study we set out to collect data from service users, network members and clinicians regarding the implementation and performance of a Peer Supported Open Dialogue service within an NHS mental health trust. Aspects investigated included model adherence; both self-reported and clinician-reported clinical outcomes; satisfaction of clinicians, service users and network members; and broad comparison data to community and crisis teams. Seikula contends that the dialogic approach does not lend itself to the power dynamics and monological approach to consent for research, however this study begins to grapple with these issues. We were required to negotiate this challenge and recruitment was successful with an acceptable level of attrition, 74\% completed the six month measures, allowing quantitative data to be collected.

Essentially the Kent POD Team is a small scale change in what is a very big system of a mental health trust within the NHS with approximately 3300 staff serving a population of 1.7 million people. It was also an enormous challenge to continue working with people until they felt they had achieved recovery and were ready for discharge rather than the clinician making those decisions as is traditional in the medical model. This follows on from the views that organisational investment is needed to allow the implementation of service user choices which included training clinicians in shared decision making as has occurred within the POD model [31].

The psychosocial model which we developed has proved to be workable. The POD team had to remain within the governance structures of a large NHS Trust. The standard operating procedure written for the team included agreements with all parts of the system as to how the POD team would interface and work safely within and seamlessly with the usual system of mental health care delivery. For example, we had to consider the care programme approach (care and treatment plan) and risk assessment and management whilst continuing to 
work Dialogically. We also monitored our concerns, incidents and performance in terms of activity, responsivity and service user and carer experience as well as ensuring there was no increased risk to any service user, family member or staff member during the course of this innovation.

Strengths

This trial was run in a real life NHS clinical setting taking a pragmatic approach.

Limitations:

This is a small scale study, not randomised and looked at one team. A full randomised control trial is therefore indicated.

\section{Conclusions}

As Peer Supported Open Dialogue Services emerge in the UK, this study provides the first evidence of clinical, social and satisfaction outcomes in mainstream mental health services. A flexible, social network response to crisis care that includes peer support workers as a key component of the care, POD, with the continuity of the same POD clinicians building a shared memory of a family's distress throughout care, represents a significantly different approach to mental health care in the UK. Clinical outcomes were consistent across mental wellbeing and work/social adjustment (self-reported) and HoNOS scores (clinician-reported) and showed that this approach is clinically effective with significant improvements across all measures. Employment and education data were less indicative but these data were collected over six months and a longer follow-up study is required. As such, this study evidencing clinical effectiveness, model adherence and satisfaction for service users and their families is sufficient to demand a full scale randomised control trial research at a national level and augurs well for its findings. Since the completion of this study this POD service has gone on to be a site in the Open Dialogue: Development and Evaluation of a Social Network Intervention for Severe Mental Illness (ODDESSI) - UK national research trial. Despite the challenges of introducing a new service that was different to existing NHS service structure and principles, the adapted POD model was closely adhered to with continuity of care from crisis through recovery being prioritised. Peer Supported Open Dialogue is an innovative and clinically effective method of treatment delivery in a large NHS mental health trust which now demands further randomised control trial research.

\section{Abbreviations}

CMHS NHS Community Mental Health Survey

CQC Care Quality Commission (NHS UK)

CRHT Crisis Resolution Home Treatment teams

CWS Carer Wellbeing and Support Scale

FYFV The Five Year Forward View for Mental Health

HoNOS Health of the Nation Outcome Scales

Page 15/19 
KMPT Kent and Medway NHS and Social Care Partnership Trust

NHS National Health Service (UK)

OD Open Dialogue

POD Peer Supported Open Dialogue

SWEMWBS Short Warwick-Edinburgh Mental Wellbeing Scale

WASAS Work and Social Adjustment Scale

\section{Declarations}

\section{Financial support}

The study was part funded by the Health Foundation's Innovating for Improvement programme but had no influence in conducting the study or writing of the paper.

\section{Conflict of interest}

The authors declare that they have no competing interests.

\section{Ethics approval and consent to participate}

The study followed established ethical principles and received Ethics approval from Camden and Kings Cross NRES Committee (Reference 16/LO/1606) and the Health Research Authority (IRAS No. 211010). Informed consent from all participants was obtained before inclusion into the study. The authors confrm that all methods were performed in accordance with the relevant guidelines and regulations.

\section{Consent for Publication}

Not Applicable

\section{Availability of data and materials}

The datasets used and/or analysed during the current study are available from the corresponding author on reasonable request.

\section{Competing interests}

The authors declare that they have no competing interests.

\section{Funding}

The study was part funded by the Health Foundation's Innovating for Improvement programme (Ref:3025). The views expressed are those of the authors and not necessarily those of the Health Foundation.

\section{Authors' Contributions}


CK, JO, YI and DM coordinated and wrote the application to the Health Foundation. JO was the Chief Investigator of the study, CK, JO, and YI shared day-to-day management of the project, DM was the project supervisor and MC was the project research assistant who recruited participants and collected the study data. All authors contributed substantially to study design, development of intervention, analysis and interpretation of findings and drafting the manuscript. All authors read and approved the final manuscript.

\section{Acknowledgements}

The authors would like to thank Annie Jeffrey, Carer Lead at Kent and Medway NHS and Social Care Partnership Trust, for advice in relation to carer support and Arti Makwana, Research Facilitator at Kent and Medway NHS and Social Care Partnership Trust, for help with the data entry.

\section{References}

1. Seikkula J, Alakare B, Aaltonen J, Holma J, Rasinkangas A, Lehtinen V. Open dialogue approach: treatment principles and preliminary results of a two-year follow-up on first episode schizophrenia. Ethical Hum Sci Serv. 2003;5(3):163-182.

2. Seikkula J. Open dialogues with clients with mental health problems and their families. Context. 2015;138:2-6.

3. Lakeman R. The Finnish open dialogue approach to crisis intervention in psychosis: a review. Psychother Aust. 2014;20(3):28-35.

4. Seikkula J, \& Olson M. The open dialogue approach to acute psychosis: its poetics and micropolitics Fam Process. 2003;42(3):403-18.

5. Olson M, Seikkula J, Ziedonis D. The key elements of dialogic practice in open dialogue: fidelity criteria. Worcester MA: University Massachusetts Medical School; 2014.

https://www.umassmed.edu/globalassets/psychiatry/opendialogue/keyelementsv1.109022014.pdf. Accessed 22 January 2021.

6. Seikkula J, Aaltonen J, Alakare B, Haarakangas K, Keränen J, Lehtinen K. Five-year experience of firstepisode nonaffective psychosis in open-dialogue approach: treatment principles, follow-up outcomes, and two case studies. Psychother Res. 2006;16(2):214-228.

7. Bergström T, Alakare B, Aaltonen J, Mäki P, Köngäs-Saviaro P, Taskila JJ, Seikkula J.. The long-term use of psychiatric services within the open dialogue treatment system after first-episode psychosis. Psychosis. 2017;9(4):310-321.

8. Freeman A, Tribe R, Stott J, Pilling S. Open dialogue: a review of the evidence. Psychiatr Serv. 2019 Jan $1 ; 70(1): 46-59$.

9. Razzaque R, Stockmann T. An introduction to peer-supported open dialogue in mental healthcare. BJPsych Advances. 2016;22:348-356.

10. Gillard S, and Holley J. Peer workers in mental health services: literature overview. Adv Psychiatr Treat 2014.;20(4), 286-292.

11. Slade M, McDaid D, Shepherd G, Williams S, Repper J. Recovery: the business case. ImRoc: Nottingham, UK. 2017. 
http://www.researchintorecovery.com/files/2017\%20ImROC\%2014\%20Recovery\%20Business\%20Case.pdf. Accessed 17 February 2021.

12. Trachtenberg M, Parsonage M, Shepherd G, Boardman J. Peer support in mental health care: is it good value for money? Centre for Mental Health: London. 2013.

http://eprints.Ise.ac.uk/60793/1/Trachtenberg_etal_Report-Peer-support-in-mental-health-care-is-it-goodvalue-for-money_2013.pdf. Accessed 22 Janaury 2021.

13. Mead S. Peer support: what is it and what makes it different? Scottish Recovery Network: Glasgow. 2011. https://www.scottishrecovery.net/resource/peer-support-what-is-it-and-what-makes-it-different. Accessed 22 Janaury 2021.

14. Osborne J, Colman M, Jeffrey A, Barker T, Bowley M, Waddingham R, Sanders B, Kinane C. The Kent and Medway NHS and Social Care Partnership Trust peer supported open dialogue service: perspectives from the team. Context, 2017;152:28-32.

15. Academy of Peer Supported Open Dialogue (APOD). 2021. http:// apopendialogue.org. Accessed 13 January 2021.

16. Osborne J, Ishaq Y, Colman M, Sanders B, Bowley M. Dialogical supervision in an NHS open-dialogue service. Context. 2017;154:46-48.

17. Andersen T. The reflecting team: dialogues and dialogues about the dialogues. New York: Norton; 1991.

18. Anderson H. In the space between people: Seikkula's open dialogue approach. J Marital Fam Ther. 2002;28:279-281.

19. Tribe R, Freeman A, Livingstone S, Stott J, Pilling S. Open dialogue in the UK: qualitative study. BJPsych Open. 2019;5(4):e49.

20. Razzaque R, Wood L. Open dialogue and its relevance to the nhs: opinions of NHS staff and service users. Community Mental Health J. 2015;51(8):931-938.

21. Kirkwood B, Sterne J. Essential Medical Statistics. 2nd Ed. Oxford: Blackwell Science; 2003.

22. Wing J, Beevor A, Curtis R, Park S, Hadden J,Burns A. Health of the nation outcome scales (HoNOS): research and development. BJPsych, 1998;172(1):11-18.

23. Tennant R, Hiller L, Fishwick R, Platt S, Joseph S, Weich S, Parkinson J, Secker J, Stewart-Brown S. The Warwick-Edinburgh mental well-being scale (WEMWBS): development and UK validation. Health Qual Life Outcomes. 2007;5:63.

24. Marks I. Behavioural psychotherapy. Bristol: John Wright; 1986.

25. Care Quality Commission. Community mental health survey: service user questionnaire. 2017. https://nhssurveys.org/wp-content/surveys/05-community-mental-health/02-surveymaterials/2017/Core\%20questionnaire.pdf. Accessed $18^{\text {th }}$ February 2021.

26. Quirk A, Smith S, Hamilton S, Lamping D, Lelliott P, Stahl D, Pinfold V, Andiappan M. Development and validation of the carer well-being and support (CWS) questionnaire. London: HMSO; 2009.

27. Ramon S. The place of social recovery in mental health and related services. Int. J. Environ. Res. Public Health. 2018; 15(6):1052.

28. Beresford P, Perring R, Nettle M, Wallcraft J. From mental illness to a social model of madness and distress. 2016. https://www.shapingourlives.org.uk/wp-content/uploads/2016/05/FROM-MENTAL- 
ILLNESS-PDF-2.pdf. Accessed 21 Janaury 2021.

29. Tansella M, Thornicroft G.. Evaluation of mental health services. In Gelder M, Andreasen N, J Lopez-lbor J, Geddes J. editors New Oxford Textbook of Psychiatry (2 ${ }^{\text {nd }}$ ed). Oxford: Oxford University Press. 2012:14631473.

30. Care Quality Commission. Right here, right now: people's experiences of help, care and support during a mental health crisis. London: Care Quality Commission. 2015.

31. Revier C, Reininghaus U, Dutta R, Fearon P, Murray R, Doody G, Croudace T, Dazzan, P, Heslin M, Onyejiaka A, Kravariti E. Ten-year outcomes of first-episode psychoses in the MRC AESOP-10 study. J Nerv Ment Dis. 2015;203(5):379-386.

32. Farrelly S, Lester H, Rose D, Birchwood M, Marshall M, Waheed W, Henderson R, Szmukler G, Thornicrof, G. Barriers to shared decision making in mental health care: qualitative study of the joint crisis plan for psychosis. Health Expec. 2015;19(2):448-458. 